\title{
Determination of genetic variations of Carasobarbus luteus populations living in Euphrates River based on mitochondrial DNA cyt b sequences
}

\author{
Ahmet OYMAK, Arif PARMAKSIZ \\ Harran University, Faculty of Science-Literature, Department of Biology, Şanlıurfa, \\ Turkey
}

\begin{abstract}
Euphrates River is an important natural resource both fish biodiversity and fishing potential. It has been detected the richest family in terms of species number is Cyprinidae. Carasobarbus luteus (Heckel, 1843) is known as the Yellow barbell and Mesopotamian himri. It is an endemic species from the family Cyprinidae possessing a wide distribution in Euphrates. It is used as food by local people and this species is also of economic importance due to high demand as food. Because of this a decrease has been observed for populations of this species. It is crucial to recognize genetic variations of populations consisting of this species for long term fishery and conservation strategies. The aim of this study is to reveal fundamental data for sustainability and conservation of the species' stocks by identifying genetic structures of $C$. luteus populations. A total number of 46 fish specimens were collected from 3 localities in the rivers systems of Euphrates and mtDNA cyt b site was analyzed by sequencing. 13 polymorphic sites and 5 haplotypes were identified in these analyses; mean haplotype and nucleotide diversity were determined to be 0.342 and 0.00504 , respectively. Information about genetic variation and population structure obtained for $C$. luteus in the this study will contribute for planning effective strategies to conserve this species.
\end{abstract}

Keywords: polymorphism, genetic diversity, population genetic, freshwater fish, Yellow barbell 